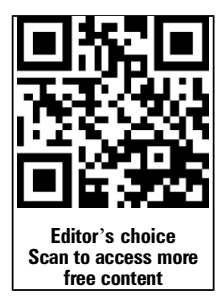

${ }^{1}$ Office on Smoking and Health, Centers for Disease Control and Prevention, Atlanta, Georgia, USA ${ }^{2}$ Public Health and Survey Research Division, ICF International, Atlanta, Georgia, USA

\section{Correspondence to} Dr Brian A King, Office on Smoking and Health, Centers for Disease Control and Prevention, 4770 Buford Highway NE, MS F-79, Atlanta, GA 30341, USA; baking@cdc.gov

Received 20 June 2014 Accepted 16 December 2014 Published Online First 7 January 2015

\title{
Smoke-free multiunit housing: a review of the scientific literature
}

\author{
Kimberly Snyder, ${ }^{1}$ Janice Hassett Vick, ${ }^{2}$ Brian A King ${ }^{1}$
}

\begin{abstract}
Objective Multiunit housing (MUH) residents are susceptible to secondhand smoke (SHS) exposure, which can transfer between living units. This review summarises existing scientific literature relevant to smoke-free MUH, discusses knowledge gaps and provides recommendations for future research to inform public health action.
\end{abstract}

Data sources We conducted a systematic search of peer-reviewed articles using three databases: EBSCOhost CINAHL, PubMed and Web of Science.

Study selection Article titles, abstracts and text were reviewed to ascertain three inclusion criteria: (1) English language; (2) conducted in the USA; (3) reported on baseline data, development, implementation or evaluation of smoke-free MUH.

Data extraction We used a multistep process to identify eligible articles: (1) two reviewers separately evaluated article titles; (2) two reviewers separately evaluated abstracts and (3) one reviewer read each article and determined inclusion eligibility.

Data synthesis We identified and included 35 articles published during 2001-2014, grouped based on broad themes: MUH resident $(n=16) ;$ MUH operator $(n=6)$; environmental monitoring and biomarkers $(n=9)$; economic $(n=2)$; legal $(n=3)$; and implementation process and policy impact $(n=8)$. Studies with multiple themes were included in all relevant groups.

Conclusions Existing literature has focused on selfreported, cross-sectional studies of MUH residents and operators; some studies of environmental markers, biomarkers and economic indicators have also been conducted. Future research on smoke-free MUH policy compliance and enforcement, and on the impact of these policies on smoking behaviours and health outcomes, could further inform public health planning, policy and practice. Despite these gaps, the current literature provides sufficient evidence for action to eliminate SHS exposure in MUH.

\section{INTRODUCTION}

Secondhand smoke (SHS) exposure from burning tobacco products causes significant disease and death among non-smoking adults and children. ${ }^{1}$ The US Surgeon General has concluded that there is no risk-free level of SHS and that full elimination of smoking indoors is the only effective way to fully protect non-smokers from the health consequences of exposure. $^{2}$ In the USA, considerable progress has been made towards increasing the number of statewide comprehensive smoke-free laws that prohibit smoking in all indoor areas of public places and worksites, including restaurants and bars. As of 31 December 2013, 26 states and the District of Columbia have enacted comprehensive smoke-free laws. ${ }^{3}$ However, these laws do not eliminate SHS exposure from all sources. Private settings, such as homes, remain a major source of SHS exposure for many people. ${ }^{2}$ On average, American adults and children spend approximately $69 \%$ of their time at home, ${ }^{4}$ which is the primary source of SHS exposure among children. $^{2}$

Individuals living in multiunit housing (MUH) are particularly susceptible to SHS exposure in the home. SHS can infiltrate smoke-free living units from units and shared areas where smoking occurs. ${ }^{5}$ Approximately 80 million Americans, representing one-quarter of the entire US population, reside in $\mathrm{MUH} ;^{6}$ approximately 7 million of these individuals reside in government-subsidised housing. ${ }^{7}$ The situation is compounded by the fact that a large proportion of populations residing in government-subsidised $\mathrm{MUH}$, particularly public housing, are already at high risk for chronic diseases and overall poorer health, including those with low income, racial/ethnic minorities, children and the elderly. ${ }^{7}$

To reduce SHS exposure in MUH, a growing number of public housing authorities, municipalities and operators of private market-rate $\mathrm{MUH}$ have implemented smoke-free building policies prohibiting smoking in indoor areas, including living units. The US Department of Housing and Urban Development (HUD) has recommended that public housing authorities, as well as operators of multifamily housing rental assistance programmes, such as Section 8, implement smoke-free building policies for some or all of their properties. ${ }^{8}$ As of 3 July 2014, less than $10 \%$ of all public housing authorities in the USA have enacted smoke-free building policies in all properties. Fifteen communities in California have adopted legislative ordinances prohibiting smoking in certain types of market-rate $\mathrm{MUH}$, including all living units; however, these policies vary with regard to the minimum number of units a building must have in order to be covered, and whether the policy covers condominiums and public/affordable housing. ${ }^{9}$

Public health concerns over SHS exposure in $\mathrm{MUH}$, as well as the proliferation of smoke-free building policies in government-subsidised and market-rate $\mathrm{MUH}$, have resulted in an increasing body of peer-reviewed literature on the issue. However, to date, no synthesis of this literature exists. To address this need, this paper summarises the current scientific evidence; discusses gaps in existing knowledge that are necessary to further inform public health planning, policy and practice; and provides recommendations for future research to fill these gaps. 


\section{METHODS}

\section{Data source}

We performed a systematic search of the scientific, peerreviewed literature related to smoke-free $\mathrm{MUH}$ in three online databases as of June 2013: (1) EBSCOhost CINAHL; (2) PubMed and (3) Web of Science.

\section{Study selection}

Search terms used for each database included: 'smoke free' or 'tobacco free' or 'smokeless' or 'tobacco regulation' or 'secondhand smoke' or 'thirdhand smoke'; and 'multiunit housing' or 'homes' or 'housing' or 'apartment' or 'housing' or 'multiunit' or 'residences'. Search alerts established for each database ensured that relevant articles published through 15 June 2014 were also considered. In total, the search yielded 1798 articles. Article titles, abstracts and full texts were then reviewed to ascertain alignment with the following inclusion criteria: (1) English language; (2) conducted in the USA and (3) reported on baseline data, development, implementation or evaluation of smoke-free MUH. Most articles were excluded while considering the third criteria because they addressed research in singlefamily homes rather than $\mathrm{MUH}$, or environmental health concerns in the home other than tobacco smoking.

\section{Data extraction}

A three step process was used to determine eligibility (figure 1): (1) two reviewers separately read titles of identified articles to determine if inclusion criteria were met and grouped abstracts as 'included', 'excluded' or 'further review required'; (2) two reviewers separately read included abstracts to determine if inclusion criteria were met and grouped articles as 'included', 'excluded' or 'further review required'. During steps 1 and 2, reviewers discussed and reconciled differences; and during step 3, the articles were divided between two reviewers and one reviewer read each article (both 'included' and 'further review required') to determine if inclusion criteria were met and grouped articles as 'included' or 'excluded'. Any articles selected for exclusion were discussed and agreed on by the other reviewer.

\section{Data synthesis}

In total, 35 articles published during 2001-2014 were selected for inclusion. Two authors divided these articles; each was read by one author and then grouped according to six recurring themes: MUH resident $(n=16)$; MUH operator $(n=6)$; environmental makers and biomarkers $(n=9)$; economic $(n=2)$; legal $(\mathrm{n}=3)$; and implementation process and policy impact studies $(\mathrm{n}=8)$. Studies with content specific to multiple themes were included in all relevant groups. Data synthesis varied by theme. For MUH resident and operator studies, findings were abstracted into a table according to publication year, study location, housing type, sample size, response rate, survey method, incentive, measures, findings and disparities. Because of the marked variations in environmental markers and biomarkers across studies, they were not summarised in a table. Instead, these studies, along with economic, legal, and implementation process and policy impact studies, were read and the findings were summarised in narrative form. For all themes, similar constructs were identified and used to inform conclusions and recommendations.

\section{RESULTS}

\section{MUH resident studies}

Study methodology

We identified 16 studies that utilised survey or interview data from MUH residents ${ }^{6}{ }^{10-23}$ (table 1). Survey size ranged from $142^{10}$ to $5936^{20}$ residents, with response rates ranging from $16 \%{ }^{11}$ to $86 \%{ }^{10}$ Prevalence of cigarette smoking varied across studies, from $8 \%{ }^{10}$ to $48 \% .{ }^{17}$ Half of the studies focused on lowincome residents and/or low-income housing. ${ }^{10-12} 1722$ In four studies, the majority of surveyed MUH residents were racial/ ethnic minorities; ${ }^{10} 111723$ in another four studies, greater than $85 \%$ were Caucasian. ${ }^{12-14} 22$ Resident age distribution varied considerably; six studies had a generally balanced age distribution, ${ }^{11} 1314202123$ while three were skewed towards younger residents. ${ }^{10} 1517$ In this review, we focused on the most frequently reported measures from the aforementioned studies, including smoke-free building policies and home rules, SHS incursions, and preference and support for smoke-free MUH.

\section{Smoke-free building policies and home rules}

In a national study of MUH residents, Licht $e t a l^{21}$ reported that in $2010,17 \%$ of smokers and $32 \%$ of non-smokers $(29 \%$ overall) reported living in a smoke-free building; additionally, those living in duplexes or multifamily homes and those with
Figure 1 Overview of inclusion and exclusion criteria and stages of the systematic review process.

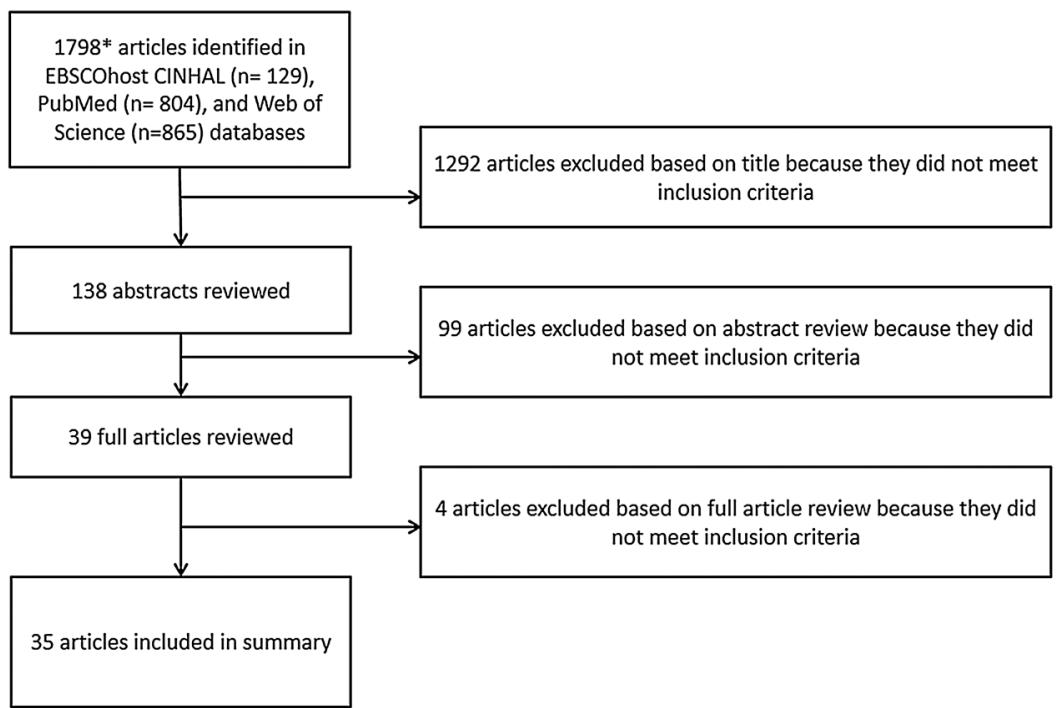

*Includes duplicates, presentation abstracts, and non-peer reviewed sources (e.g. Newsweek) and 3 additional articles identified after full search through search alerts 
Table 1 Summary of peer-reviewed literature presenting findings from surveys of multiunit housing residents*

\begin{tabular}{|c|c|c|c|c|c|c|c|c|c|c|}
\hline Lead author & Year & Location & Racial/ethnic minority & Housing type & $\begin{array}{l}\text { Per cent } \\
\text { female }\end{array}$ & $\begin{array}{l}\text { Current } \\
\text { smokers }\end{array}$ & Sample size & Response rate & Survey method & Participant incentive \\
\hline Baezconde-Garbanati & 2011 & $\begin{array}{l}\text { Southern } \\
\text { California }\end{array}$ & $\begin{array}{l}\text { Not specified (Hispanic/ } \\
\text { Latino immigrant focus) }\end{array}$ & $\begin{array}{l}\text { Low-income } \\
\text { housing }\end{array}$ & 56 & Not reported & 142 & $86 \%$ & Verbal (door-to-door) & $\begin{array}{l}\text { Educational pamphlets; } \\
\text { small gifts }\end{array}$ \\
\hline Baezconde-Garbanati† & 2011 & $\begin{array}{l}\text { Southern } \\
\text { California }\end{array}$ & $\begin{array}{l}100 \% \text { minority } \\
\text { (Hispanic/Latino) }\end{array}$ & Rented MUH & 49 & $8 \%$ & 409 & Not reported & Telephone & None \\
\hline Ballor & 2013 & $\begin{array}{l}\text { Tacoma, } \\
\text { Washington }\end{array}$ & $54 \%$ minority & $\begin{array}{l}\text { Public housing } \\
\text { (apartments) }\end{array}$ & 67 & $37 \%$ & 229 & $\begin{array}{l}16 \% \text { of units } \\
\text { targeted }\end{array}$ & $\begin{array}{l}\text { Paper (central office } \\
\text { or taped to doors) }\end{array}$ & None \\
\hline Drach & 2010 & $\begin{array}{l}\text { Portland, Oregon } \\
\text { Metropolitan area }\end{array}$ & $13 \%$ minority & $\begin{array}{l}\text { Subsidised } \\
\text { housing } \\
\text { (apartments) }\end{array}$ & 69 & $36 \%$ & 687 & $82 \%$ & Paper (mailing) & $\begin{array}{l}\text { \$2 incentive with } \\
\text { mailing; } \$ 25 \text { for } \\
\text { completion }\end{array}$ \\
\hline Hennrikus & 2003 & $\begin{array}{l}\text { Suburban } \\
\text { Minneapolis, } \\
\text { Minnesota }\end{array}$ & $\begin{array}{l}\text { Not reported for sample } \\
\text { (suburb } 91 \% \text { white) }\end{array}$ & $\begin{array}{l}\text { Market-rate } \\
\text { housing } \\
\text { (apartments) }\end{array}$ & 56 & $24 \%$ & 301 & $65 \%$ & Paper (mailing) & None \\
\hline Hewett & 2007 & $\begin{array}{l}\text { Minnesota } \\
\text { (statewide) }\end{array}$ & $28 \%$ minority & $\begin{array}{l}\text { Market-rate } \\
\text { housing } \\
\text { (apartments) }\end{array}$ & $\begin{array}{l}\text { Not } \\
\text { reported }\end{array}$ & $\begin{array}{l}29 \% \text { of } \\
\text { respondent } \\
\text { households }\end{array}$ & 405 & $71 \%$ & $\begin{array}{l}\text { Paper (mailing) and } \\
\text { telephone }\end{array}$ & $\begin{array}{l}\$ 2 \text { incentive with } \\
\text { mailing; chance to win } \\
\$ 1000 \text { for completion }\end{array}$ \\
\hline Hewett & 2012 & $\begin{array}{l}\text { Minnesota } \\
\text { (statewide) }\end{array}$ & $4.7 \%$ minority & $\begin{array}{l}\text { Common interest } \\
\text { communities }\end{array}$ & $\begin{array}{l}\text { Not } \\
\text { reported }\end{array}$ & $15 \%$ & 495 & $36 \%$ & $\begin{array}{l}\text { Paper (mailing) and } \\
\text { telephone }\end{array}$ & None \\
\hline Hood* & 2013 & Columbus, Ohio & $84 \%$ African-American & $\begin{array}{l}\text { Subsidised } \\
\text { housing } \\
\text { (apartments) }\end{array}$ & 86 & $48 \%$ & 301 & $64 \%$ & $\begin{array}{l}\text { Verbal (resident } \\
\text { homes after advance } \\
\text { mailing) }\end{array}$ & $\$ 5$ grocery store gift card \\
\hline King & 2010 & $\begin{array}{l}\text { New York } \\
\text { (statewide) }\end{array}$ & $43 \%$ minority & General MUH & 66 & $19 \%$ & 5936 & $33 \%$ & Telephone & $\$ 20$ for completion \\
\hline Licht & 2012 & National & Not reported & General MUH & $\begin{array}{l}\text { Not } \\
\text { reported }\end{array}$ & Not reported & 164 (landline); 254 (cell) & $\begin{array}{l}44 \% \text { (landline); } \\
31 \% \text { (cell) }\end{array}$ & Telephone & None \\
\hline Pizacanił & 2012 & Portland, Oregon & $12 \%$ minority & $\begin{array}{l}\text { Subsidised } \\
\text { housing }\end{array}$ & 69 & $18 \%$ & 440 & $78 \%$ & Paper (mailing) & $\begin{array}{l}\$ 2 \text { bill at time of } \\
\text { mailing; } \$ 25 \text { for } \\
\text { completion }\end{array}$ \\
\hline Wilson & 2014 & National & $\begin{array}{l}23 \% \text { African-American } \\
30 \% \text { other }\end{array}$ & General MUH & 52 & $12 \%$ & $\begin{array}{l}731 \text { MUH residents ( } \mathrm{n}=562 \\
\text { who reported no past } \\
\text { 3-month smoking in home) }\end{array}$ & $\begin{array}{l}86 \% \text { (telephone); } \\
65 \% \text { (internet) }\end{array}$ & $\begin{array}{l}\text { Telephone and } \\
\text { internet }\end{array}$ & None reported \\
\hline
\end{tabular}

${ }^{*}$ Four papers relevant to the MUH resident section of this review are not included in this table. King et $a l^{6}$ is not included because the data come from secondary data sources. Hood et $a l{ }^{16}$ Hood et al ${ }^{18}$ and Hood et al ${ }^{19}$ are not included because the relevant survey data are the same data reported in Hood et al, ${ }^{17}$ which is listed in the table above.

tReported on two surveys within the same published paper: as indicated, one was a door-to-door survey, and the other was a telephone survey.

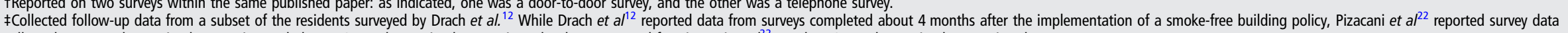
collected at 4 months postimplementation and about 16 months postimplementation. The data presented for Pizacani et $a^{P^{22}}$ are the 16 months postimplementation data. MUH, multiunit housing. 
children were more likely to live in a smoke-free building. A second national study in 2014 found that approximately $47 \%$ of residents reported living in a smoke-free building or property. ${ }^{23}$ However, other studies reveal that residents are often uncertain of existing regulations. For example, Hennrikus et $a l^{13}$ found disagreement among renters living in the same complex; 7\% reported living in a completely smoke-free building, $55 \%$ reported public areas of their building were smokefree, $29 \%$ reported that their building had no smoking-related policies, $8 \%$ reported that their building had some type of policy and 5\% reported they did not know what the policy was. Similarly, Hewett et al ${ }^{15}$ found that $14 \%$ of renters reported living in smoke-free buildings, while building operators estimated that just $2.4 \%$ of the renter population lived in such buildings.

Most studies that assessed home smoking rules found that a majority of residents had voluntarily prohibited smoking in their own units, ranging from $50 \%{ }^{17}$ to over $95 \% .^{10}$ Among current smokers, smoke-free home rules ranged from $6 \%{ }^{17}$ to $53 \% .{ }^{11}$ Two national studies revealed similar results on the percentage of MUH residents with smoke-free homes. One revealed that $73 \%$ of MUH residents $(81 \%$ of non-smokers and $35 \%$ of smokers) had voluntary smoke-free home rules, ${ }^{21}$ while the other found that $77 \%$ of MUH residents had no home smoking in the previous 3 months $^{23}$ (table 2). Three studies examined associations between smoke-free home rules and a variety of demographic characteristics. ${ }^{13} 20{ }^{21}$ Respondents with smoke-free home rules were more likely to have more education $^{20} 21$ or children living in the home. ${ }^{20} 21$ Although a New York study found that Hispanics were more likely to have smoke-free home rules, ${ }^{20}$ a national study found no differences by race/ethnicity. ${ }^{21}$ Factors associated with lower likelihood of having a smoke-free home rule included older age, having more than a few smoker friends, and having a smoker living in the household. ${ }^{13}$ Residents living in a duplex or condominium were more likely to have a smoke-free home rule in one study, ${ }^{20}$ while another found no association with MUH type. ${ }^{21}$

\section{SHS incursions}

Across resident surveys, residents have been asked about SHS exposure in their homes from external sources (ie, SHS incursions) in variable ways. Some have asked residents about SHS 'drifting' into the apartment, ${ }^{10}$ while some have asked how often or whether they have smelled, breathed or noticed odours of tobacco smoke coming from other sources, ${ }^{11} 13151722$ and others have asked about cigarette or tobacco smoke entering or coming into their unit or living space from other sources. ${ }^{14}{ }^{20} 21$ Additionally, one study asked residents who reported smelling tobacco smoke in their building whether they ever smell tobacco smoke inside their unit. $^{23}$ Studies have also been variable in assessments of the frequency of exposure and in defining exposure timeframes (eg, past 6 or 12 months). Moreover, although some studies restricted SHS incursion questions to residents with smoke-free home rules, ${ }^{20} 21$ most studies asked all residents about SHS incursions. The proportion of residents self-reporting that they had experienced SHS incursions in their units was generally high, with prevalence ranging from $26 \%$ to $64 \%$ (see table 2). Using secondary data, King et $a l^{6}$ developed national and state estimates of SHS incursions among US MUH residents with smoke-free home rules, estimating that 27.6-28.9 million experienced SHS incursions each year.

Studies of MUH residents indicate higher likelihood of selfreported SHS incursions among females, respondents with children living in the household and households living below the poverty level. ${ }^{2021}$ Findings for respondents with children living in the household are mixed, with two studies finding a higher likelihood of self-reported SHS incursions, ${ }^{20}{ }^{21}$ and one study finding a lower likelihood of self-reported SHS incursions. ${ }^{23}$ In two studies, older individuals were less likely to report experiencing incursions. ${ }^{20}{ }^{21}$ However, Hewett $e t$ al ${ }^{15}$ found no difference in SHS incursions between senior and non-senior respondents. Similarly, Hispanic residents were more likely to report experiencing a SHS incursion in one study, ${ }^{20}$ though a second reported no differences by race/ethnicity. ${ }^{15}$ King et al reported no association between SHS incursions and either educational attainment or geographic location within New York, but Wilson $e a^{23}$ found that residents with no more than a high school education were less likely to report SHS incursions than those with at least a bachelor's degree. Building characteristics were also assessed for relationships to residents' experiences of incursions. Those living in a duplex, double or multifamily home, or a condominium were less likely to experience incursions; ${ }^{20}$ similarly, those living in one-family attached homes were less likely to report SHS incursions than those living in apartments or condominiums. ${ }^{23}$ Also, those living in buildings more than 20 years old reported more frequent incursions. ${ }^{15}$ In one study, residents living in MUH where smoking is allowed in units were more likely to report SHS incursions compared with residents living in MUH where smoking was not allowed. ${ }^{23}$ Among residents who experienced incursions, the proportion that was bothered by the incursions ranged from $65 \%$ to $90 \% .^{10} 13-1520$

\section{Preference and support for smoke-free MUH}

Eight studies assessed residents' preferences or support for a smoke-free building. ${ }^{10} \quad 11 \quad 13-15 \quad 17 \quad 20 \quad 21$ In all but two studies, ${ }^{10} 14$ the majority of residents expressed a preference for a smoke-free building. In one study with less than a majority expressing preference for a smoke-free building (37\%), the question was worded as a complete indoor and outdoor smoking ban; $;^{10}$ in the other study where less than a majority (42\%) expressed preference for a building policy, $32 \%$ of residents indicated that they had no preference. ${ }^{14}$

Residents' support for smoke-free MUH was assessed by many demographic and behavioural characteristics. Support for smoke-free buildings was stronger among non-smokers than smokers, though some smokers were supportive of such policies (table 2). Among the seven studies examining support by smoker status, between $8 \%{ }^{15}$ and $41 \%{ }^{11}$ of smokers expressed support. Hood et $a l^{17}$ found that never-smokers were more likely to support smoke-free MUH than current or former smokers; among current smokers, those who intended to quit within 6 months were more likely to support in-unit policies. Additionally, those with partial or complete smoke-free home rules were more likely to favour in-unit restrictions. Residents who experienced SHS incursions at least once a year were also more supportive of in-unit restrictions. ${ }^{17}$

Findings on preference for smoke-free building policies based on demographic factors were mixed. In two studies, racial/ ethnic minorities were more likely to favour a smoke-free building policy ${ }^{15}{ }^{20}$ but another study found no relationship by race/ ethnicity. ${ }^{17}$ Two studies ${ }^{17}{ }^{20}$ found that men were less likely to favour smoke-free $\mathrm{MUH},{ }^{17}$ while another study found no association with sex. ${ }^{13}$ One study found that educational attainment was unrelated to smoke-free MUH support, ${ }^{13}$ while two other studies found conflicting results related to education and policy support. ${ }^{17}{ }^{20}$ One study assessed associations by MUH type and found that residents living in a townhouse were less likely to 


\begin{tabular}{|c|c|c|c|c|c|c|c|}
\hline Lead author & Year & $\begin{array}{l}\text { Current smoking } \\
\text { status }\end{array}$ & $\begin{array}{l}\text { Voluntary smoke-free } \\
\text { home rule }(\%)\end{array}$ & $\begin{array}{l}\text { Experience SHS } \\
\text { incursions (\%) }\end{array}$ & $\begin{array}{l}\text { Bothered by SHS } \\
\text { incursions (\%) }\end{array}$ & $\begin{array}{l}\text { Support/prefer } \\
\text { smoke-free building (\%) }\end{array}$ & Other assessed indicators \\
\hline Baezconde-Garbanati* & 2011 & $\begin{array}{l}\text { Non-smokers } \\
\text { Smokers } \\
\text { All }\end{array}$ & $\begin{array}{l}- \\
- \\
-\end{array}$ & $\begin{array}{l}- \\
- \\
35\end{array}$ & $\begin{array}{l}- \\
- \\
66\end{array}$ & $\begin{array}{l}- \\
\overline{80}\end{array}$ & Attitudes towards SHS \\
\hline Baezconde-Garbanati† & 2011 & $\begin{array}{l}\text { Non-smokers } \\
\text { Smokers } \\
\text { All }\end{array}$ & $\begin{array}{l}- \\
\overline{95}\end{array}$ & $\begin{array}{l}64 \\
53 \\
63\end{array}$ & $\begin{array}{l}- \\
- \\
-\end{array}$ & $\begin{array}{l}37 \ddagger \\
18 \\
-\end{array}$ & $\begin{array}{l}\text { Partial policies; attitudes towards SHS; beliefs about smoke-free } \\
\text { policies }\end{array}$ \\
\hline Ballor & 2013 & $\begin{array}{l}\text { Non-smokers } \\
\text { Smokers } \\
\text { All }\end{array}$ & $\begin{array}{l}90 \ddagger \\
53 \\
-\end{array}$ & $\begin{array}{l}- \\
- \\
64\end{array}$ & $\begin{array}{l}- \\
- \\
-\end{array}$ & $\begin{array}{l}82 \ddagger \\
41 \\
-\end{array}$ & $\begin{array}{l}\text { Intention to quit; past cessation attempts; attitudes towards } \\
\text { smoke-free policies; knowledge about cessation assistance }\end{array}$ \\
\hline Drach & 2010 & - & - & - & - & - & Favourability towards current smoke-free policy; compliance \\
\hline Hennrikus & 2003 & $\begin{array}{l}\text { Non-smokers } \\
\text { Smokers } \\
\text { All }\end{array}$ & $\begin{array}{l}72 \ddagger \\
25 \\
60\end{array}$ & $\begin{array}{l}53 \ddagger \\
35 \\
46\end{array}$ & $\begin{array}{l}97 \ddagger \\
69 \\
90\end{array}$ & $\begin{array}{l}79 \neq \\
18 \\
64\end{array}$ & $\begin{array}{l}\text { Perceived enforcement issues; actions to avoid SHS; attitudes } \\
\text { towards SHS }\end{array}$ \\
\hline Hewett§ & 2007 & $\begin{array}{l}\text { Non-smokers } \\
\text { Smokers } \\
\text { All }\end{array}$ & $\begin{array}{l}77 \ddagger \\
16 \\
59\end{array}$ & $\begin{array}{l}- \\
- \\
48\end{array}$ & $\begin{array}{l}- \\
- \\
79\end{array}$ & $\begin{array}{l}63 \ddagger \\
8 \\
70\end{array}$ & Existing policy; perceived market for smoke-free units \\
\hline Hewett & 2012 & $\begin{array}{l}\text { Non-smokers } \\
\text { Smokers } \\
\text { All }\end{array}$ & $\begin{array}{l}89 \ddagger \\
32 \\
80\end{array}$ & $\begin{array}{l}30 \neq \\
13 \\
28\end{array}$ & $\begin{array}{l}969 \\
15 \\
89\end{array}$ & $\begin{array}{l}47 \\
18 \\
42\end{array}$ & $\begin{array}{l}\text { Existing policy; perceived market for smoke-free units; attitudes } \\
\text { towards existing policy }\end{array}$ \\
\hline Hood & 2013 & $\begin{array}{l}\text { Non-smokers } \\
\text { Smokers } \\
\text { All }\end{array}$ & $\begin{array}{l}50 \ddagger \\
6 \\
-\end{array}$ & $\begin{array}{l}32 \\
26 \\
-\end{array}$ & $\begin{array}{l}- \\
- \\
-\end{array}$ & $\begin{array}{l}72 \neq \\
36 \\
55\end{array}$ & $\begin{array}{l}\text { Attitudes towards SHS; nicotine dependence; intentions to quit; } \\
\text { perceived enforcement issues }\end{array}$ \\
\hline King & 2010 & $\begin{array}{l}\text { Non-smokers } \\
\text { Smokers } \\
\text { All }\end{array}$ & $\begin{array}{l}81 \neq \\
35 \\
73\end{array}$ & $\begin{array}{l}47 \ddagger \\
38 \\
46\end{array}$ & $\begin{array}{l}- \\
- \\
77\end{array}$ & $\begin{array}{l}62 \ddagger \\
27 \\
56\end{array}$ & No other assessed indicators \\
\hline Licht & 2012 & $\begin{array}{l}\text { Non-smokers } \\
\text { Smokers } \\
\text { All }\end{array}$ & $\begin{array}{l}91 \neq \\
43 \\
79\end{array}$ & $\begin{array}{l}44 \\
39 \\
44\end{array}$ & $\begin{array}{l}- \\
- \\
-\end{array}$ & $\begin{array}{l}- \\
- \\
56\end{array}$ & Existing policy \\
\hline Pizacani (baseline) & 2012 & $\begin{array}{l}\text { Non-smokers } \\
\text { Smokers } \\
\text { All }\end{array}$ & $\begin{array}{l}- \\
- \\
-\end{array}$ & $\begin{array}{l}- \\
- \\
419\end{array}$ & $\begin{array}{l}- \\
- \\
-\end{array}$ & $\begin{array}{l}- \\
- \\
-\end{array}$ & Policy awareness; compliance; smoking behaviour \\
\hline Pizacani (follow-up) & 2012 & $\begin{array}{l}\text { Non-smokers } \\
\text { Smokers } \\
\text { All }\end{array}$ & $\begin{array}{l}- \\
- \\
-\end{array}$ & $\begin{array}{l}- \\
- \\
179\end{array}$ & $\begin{array}{l}- \\
- \\
-\end{array}$ & $\begin{array}{l}- \\
- \\
-\end{array}$ & Policy awareness; compliance; smoking behaviour \\
\hline Wilson & 2014 & $\begin{array}{l}\text { Non-smokers } \\
\text { Smokers } \\
\text { All }\end{array}$ & $\begin{array}{l}78^{* *}, 88 t \dagger \\
22^{* *}, 12+\dagger \\
-\end{array}$ & $\begin{array}{l}- \\
- \\
16+\dagger\end{array}$ & $\begin{array}{l}- \\
- \\
-\end{array}$ & $\begin{array}{l}- \\
- \\
-\end{array}$ & Frequency of SHS incursions; location of SHS incursion \\
\hline
\end{tabular}


favour a smoke-free building policy. ${ }^{20}$ Two studies examined whether metropolitan versus non-metropolitan location were related to support; Hewett et $a l^{15}$ reported no relationship among a sample of Minnesota MUH residents, while King et $a l^{20}$ found that New York City MUH residents were less likely to favour a building policy compared with those living in the rest of the state. Findings for variables related to children were mixed. While one study found that residents with a child in the home were more likely to favour smoke-free $\mathrm{MUH}^{20}$ another found no relationship. ${ }^{15}$ A third study found that residents with young children in the home were more likely to support a smoke-free building policy than those with no children or older children; however, this association was not significant after controlling for smoking status. ${ }^{17}$ No association with

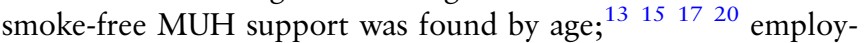
ment status; ${ }^{17}$ poverty status, income categories or rent levels; ${ }^{15}$ building safety, neighbourhood cohesion, neighbourhood conditions, unit location (ground or upper floor); or for the presence of a covered front porch. ${ }^{17}$

\section{MUH operator studies}

Study methodology

Six of the identified studies included a survey of MUH operators, which included landlords, owners, managers and/or employees $^{15}{ }^{24-28}$ (table 3). Sample size ranged from $11^{27}$ to $263,{ }^{24}$ with response rates ranging from $30.1 \%{ }^{23}$ to $62 \% .^{26}$ Two studies did not report response rates. ${ }^{15} 27$ The most frequently assessed measures included: smoke-free building policies, SHS incursions, preference/support for smoke-free MUH, perceived barriers and motivators towards smoke-free building policies, and compliance ${ }^{15}$ 24-28 $^{\text {(table 4). }}$

\section{Smoke-free building policies}

MUH operators from Oregon, Virginia, Nebraska, Minnesota and New York reported having complete smoke-free building policies or partial smoke-free policies for at least some of their properties. ${ }^{15}$ 24-28 Partial smoke-free policies include those policies in which indoor smoking is not completely prohibited in all indoor areas, including living units. ${ }^{15}{ }^{24-28}$ Smoke-free policies were reported in at least one of the following: interior common areas (eg, lobby), private residential units or exterior common areas (eg, building entry way). ${ }^{15}$ 24-28 Four studies reported prevalence of smoke-free policies as a percentage of buildings owned by MUH operators, ${ }^{24-27}$ one study reported the total number of operators with at least one policy and total number of buildings with a policy, ${ }^{15}$ and one study only included operators with a policy in place. ${ }^{28}$ Across all studies, the prevalence of smoke-free building policies within all private residential units ranged from $9 \% 0^{27}$ to $19 \%{ }^{26}$ of all buildings. Two studies reported partial building policies in interior or exterior common areas, with prevalence ranging from $10 \%{ }^{24}$ to $34 \% .^{25}$ In Minnesota, 20 operators had designated at least one or more buildings as smoke-free, with a total of 110 smoke-free buildings reported. ${ }^{15}$ Factors associated with having a smokefree building policy included senior housing, ${ }^{15} 25$ housing markets that catered to higher income residents and public housing properties, ${ }^{25}$ and newer buildings. ${ }^{27}$

\section{SHS incursions}

Two studies asked MUH operators if SHS transferred between living units. ${ }^{15} 25$ Each showed some operator recognition of SHS transfer between units, but many operators did not report it as a possibility or problem. In one study, 53\% of operators believed SHS could drift between units. ${ }^{25}$ In another study,

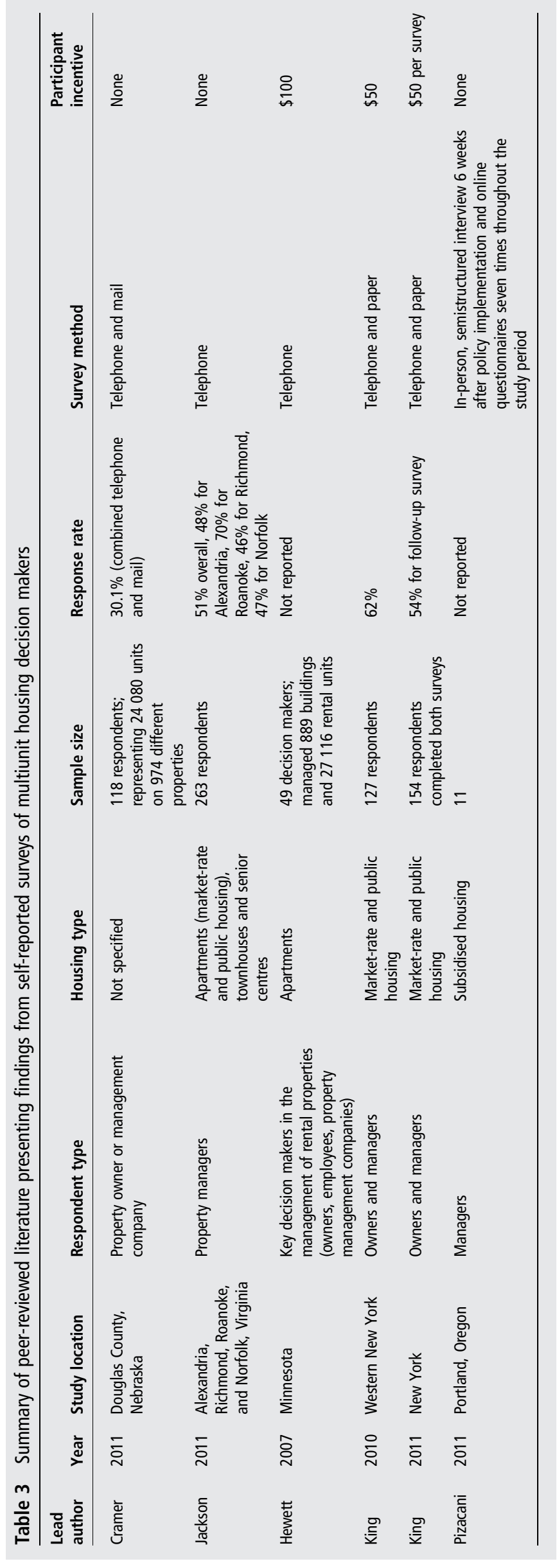




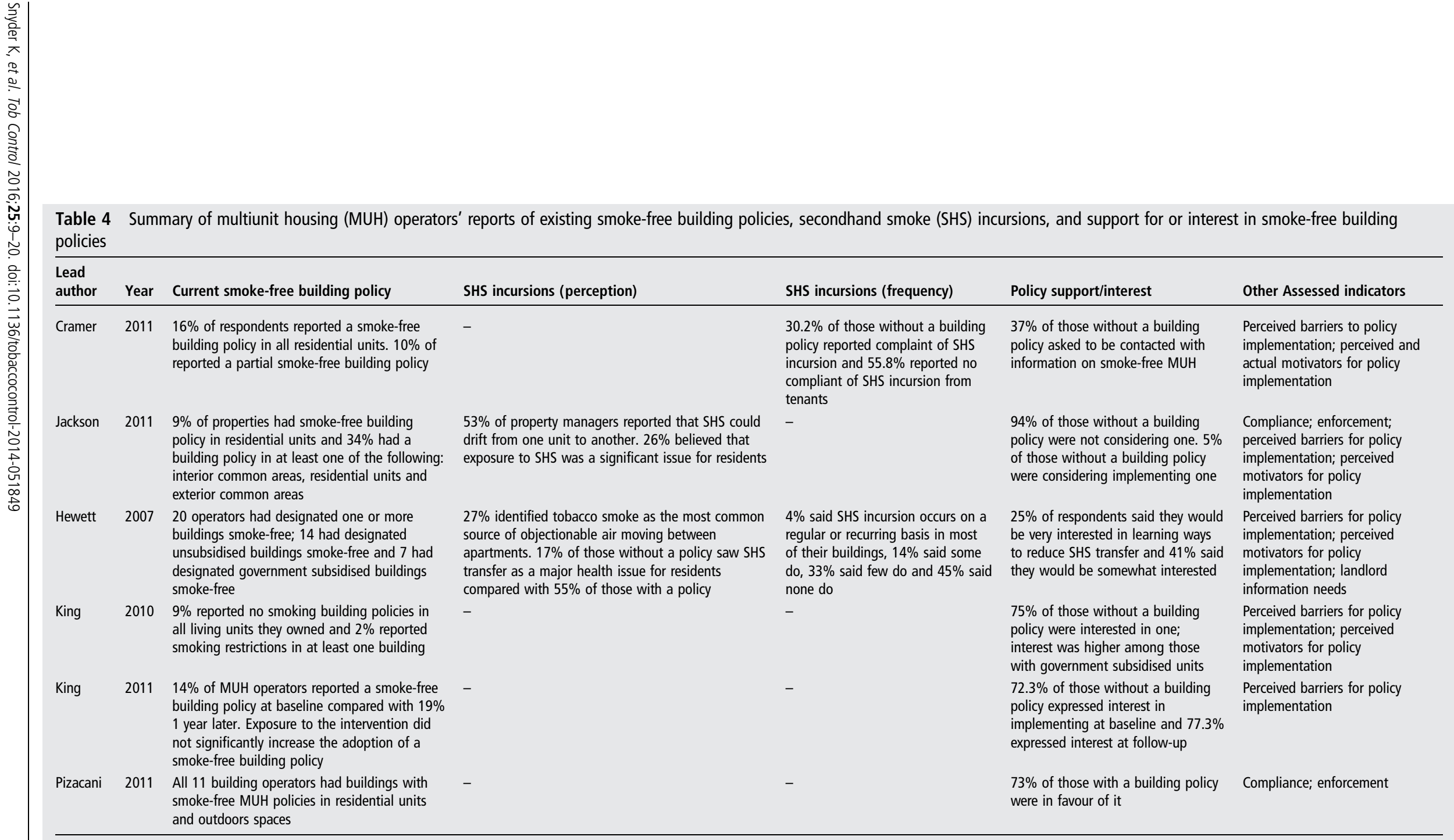


$27 \%$ of operators thought SHS was the most common substance transferring between units and $45 \%$ of operators reported no buildings they managed experienced SHS incursions on a recurring basis. ${ }^{15}$ Hewett et al ${ }^{15}$ found that more operators with policies in place reported SHS incursions as a health concern for residents (55\%) than those without such policies (17\%). Among MUH operators with no smoke-free building policy, those with HUD-subsidised units were more likely to receive complaints from residents about SHS incursions. ${ }^{27}$

\section{Preference and support for smoke-free MUH}

Five studies examined MUH operators' support for smoke-free MUH building policies. ${ }^{15}$ 25-27 Two studies found that a majority of operators without a smoke-free building policy were not considering adopting one. ${ }^{1525}$ Between $5 \%$ and $75 \%$ of operators had some level of interest in smoke-free MUH. ${ }^{15}$ 25-27 Reasons for smoke-free MUH interest included: a better environment for residents; improving residents' health; fewer conflicts between residents; lower maintenance costs; lower smoke-related damage to units and the ability to attract 'better' residents or non-smokers. ${ }^{15}{ }^{25}$ Among Minnesota MUH operators without a smoke-free building policy, half thought there was a viable market for smoke-free MUH. ${ }^{15}$ Greater interest towards smoke-free MUH policies was observed among operators of government-subsidised units, ${ }^{26}{ }^{27}$ those who received mail-based information on smoke-free MUH benefits ${ }^{26}$ and those with wood-framed buildings. ${ }^{26}$

\section{Perceived barriers and motivators towards smoke-free MUH} building policies

Five studies explored MUH operators' perceived barriers to implementing smoke-free building policies. ${ }^{15} 24-27$ MUH operators without smoke-free building policies noted the following perceived barriers: implementation and enforcement issues; ${ }^{15} 2425$ objections from existing residents; ${ }^{24}$ concerns about limiting the potential pool of residents; $;^{15}{ }^{24-27}$ concern about legality and liability; ${ }^{15} \quad 24 \quad 25 \quad 27$ increased vacancy; $;^{15} 242627$ increased turnover ${ }^{24} 27$ and increased staff time. ${ }^{27}$ Four studies explored motivating factors for MUH operators. $^{15} 242527$ Motivators included: decreased maintenance costs; ${ }^{15} 2425$ decreased management time; ${ }^{24}$ ability to charge increased rent; ${ }^{24} 2527$ decreased fire and insurances costs; ${ }^{25}{ }^{27}$ reduced resident turnover; ${ }^{27}$ free advertising of smoke-free units by local health organisations; ${ }^{27}$ ability to attract more non-smokers; ${ }^{15}$ fewer residents conflicts ${ }^{15}$ and better resident health. ${ }^{15} 25$

Results from four surveys of MUH operators with smoke-free building policies found generally neutral or positive

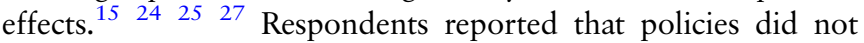
affect vacancy rates, ${ }^{15} 24$ turnover rates, ${ }^{15}{ }^{24}$ rental costs, ${ }^{15} 24$ maintenance $\operatorname{costs}^{24}$ or management time. ${ }^{15} 24$ One study reported that about half of MUH operators believed the policy decreased staff time to manage the building. ${ }^{15}$ In another study, a majority of operators with a smoke-free building policy reported that they 'never' receive complaints about the policy. ${ }^{25}$ In a separate study, all respondents with smoke-free building policies reported it was likely they would keep them. ${ }^{27}$ Two studies compared MUH operators with and without smoke-free building policies; ${ }^{1524}$ those without policies had more negative expectations of policy impact on vacancy and turnover rates than what was actually experienced by those with smoke-free buildings. ${ }^{15} 24$ Those without policies thought a policy would increase legal risks and costs; however, only one operator with a policy had to enforce their lease against a non-compliant tenant, and none reported any legal action against them. ${ }^{15}$

Smoke-free building policy compliance

Three studies assessed compliance with existing smoke-free MUH building policies, ${ }^{15} 2225$ which varied across studies. In one study, operators reported that about half of their residents or their guests had violated the smoke-free building policy. ${ }^{25}$ The other two studies reported on complaints of violation of the policy. ${ }^{1522}$ In one of these studies, three operators reported complaints, ${ }^{15}$ while in the other, operators reported few complaints; approximately one per month per building from nonsmokers about violations, and one per quarter per building from smokers who did not like the policy. ${ }^{22}$ Almost all of the operators in one study reported that they actively enforced the policy ${ }^{25}$; written warnings to violators were a common enforcement methods reports in two studies. ${ }^{22} 25$ Two studies reported evictions due to violation of the smoke-free policy, ${ }^{22}{ }^{25}$ with one reporting 11 evictions. ${ }^{22}$ Another study reported that no surveyed operators evicted a resident for violating the policy. ${ }^{25}$ Vacancy and turnover rate concerns expressed by operators without smoke-free policies ${ }^{15} 2^{24-27}$ were largely unfounded based on the reported experiences of operators with existing smoke-free building policies. ${ }^{24}$ These results suggest the importance of correcting a number of scientific and legal misperceptions held by many operators related to policy impact, ${ }^{25}$ particularly in lower priced housing markets and operators of townhouse and apartment properties where scientific and legal misperceptions are prominent. ${ }^{25}$

\section{Environmental monitoring and biomarkers studies}

Nine studies of MUH units and residents focused on measuring environmental markers of SHS or on measuring human biomarkers of SHS exposure. 51619 29-34 Specific markers measured by the studies included $\mathrm{PM}_{2.5}$, nicotine and cotinine. $\mathrm{PM}_{2.5}$, a type of particulate matter with a diameter less than $2.5 \mu \mathrm{m}$, is an environmental marker for SHS. ${ }^{35}$ Nicotine, a constituent of cigarettes, is another environmental marker of SHS measured using passive air monitors. ${ }^{31}$ Cotinine is a human metabolite of nicotine that comes from exposure to tobacco smoke. Cotinine can be measured in saliva, urine or blood. ${ }^{32}$

The studies of nicotine concentrations, air exchange rates and $\mathrm{PM}_{2.5}$ confirm that SHS can transfer between units in MUH. One study of low-income MUH measured nicotine concentrations and air exchange rates. Nicotine measurements were associated with the number of smokers in the household and cigarettes smoked, but increased levels of nicotine concentration among non-smoking residences suggested transfer of SHS from smoke-permitted units into smoke-free units. ${ }^{31}$ Another study using $\mathrm{PM}_{2.5}$ documented the transfer of SHS from smokepermitted units into 2 of 14 smoke-free units and 6 of 8 adjacent hallways within the same building. ${ }^{5}$ A final study measured $\mathrm{PM}_{2.5}$ and nicotine concentrations in common areas of a sample of Boston Housing Authority properties and found variations in SHS exposure by season, building type and resident smoking policies; ${ }^{34}$ concentrations of both markers were higher during the winter, in high-rise buildings with elderly disabled occupants, and in buildings without smoke-free policies. ${ }^{34}$

Cotinine studies with MUH residents have confirmed that non-smokers have detectable levels of cotinine in saliva and blood, suggesting evidence of SHS exposure. In one study, almost all sampled Boston Public Housing residents (88\%) had detectable levels of salivary cotinine. The study's sample of nonsmoking residents had mean cotinine levels five times higher 
than non-smoking Americans nationally. ${ }^{32}$ In another national study, children living in apartments had mean serum cotinine levels $45 \%$ higher than children living in detached houses. ${ }^{33}$

Some studies have confirmed that certain methods of limiting exposure to SHS in MUH are not entirely effective in preventing the transfer of SHS between units. One study tried to prevent the transfer of SHS by treating units (eg, sealing leakage paths between units; improving ventilation and balancing ventilation flows). ${ }^{29}$ Although premeasures/postmeasures of air flow and nicotine showed a median decrease of $29 \%$ in the proportion of transferred air and nicotine concentrations, these treatments could not effectively eliminate SHS transfer. Another study found that smoke-free home rules in subsidised multiunit housing reduced, but did not eliminate, in-home smoking; residents reported that they sometimes made exceptions to their own rules and surface nicotine concentrations confirmed such exceptions. ${ }^{19}$

Three studies made recommendations for measurement of smoking behaviours and SHS in future studies. ${ }^{16} 3031$ Dacunto et $a l^{30}$ recommended that SHS transfer between units be measured via particle size, particle compositions and volatile organic compounds. Two studies used nicotine measures and showed that self-reported data provided valid estimates, including in-home smoking behaviours ${ }^{16}$ and residential exposure to tobacco smoke. ${ }^{31}$ For future evaluation, one study suggested comparing surface nicotine concentrations between units in buildings with and without smoke-free policies, or before and after policy adoption. ${ }^{16}$

\section{Economic studies}

The two known studies of the economic impact of smoke-free MUH have generally focused on cost savings that can be realised through the implementation of these policies. ${ }^{36} 37$ Ong et al ${ }^{37}$ surveyed operators in California about their costs related to smoking and smoke-free policies. Although properties with smoke-free building policies still incurred costs related to smoking, these costs were lower and less frequent compared with those with only partial or no smoke-free building policies. Overall, the authors found that implementing complete smokefree building policies for MUH across the state would save operators over $\$ 18$ million per year. ${ }^{37}$ King et $a l^{36}$ took a broader approach in estimating the cost savings associated with prohibiting smoking in subsidised housing in the USA, including estimations of savings in SHS-related healthcare expenditures, renovation expenses and smoking-attributable fire losses. This approach led to an estimated \$521 million in cost savings annually, including $\$ 154$ million per year in public housing. ${ }^{36}$

\section{Legal studies}

Legal assessments of smoke-free MUH policies have made the case that such policies are legally permissible in all states. ${ }^{38}$ Such assessments emphasise that federal laws do not provide protection for the right to smoke, ${ }^{39}$ and that smoking has the potential for harmful effects on others. ${ }^{40}$ These assessments have included an emphasis on the operator liability risks of not implementing smoke-free building policies. ${ }^{40}$ They have also indicated that while such policies raise potential arguments related to restrictions of freedoms for the poorest, smoke-free building policies are a form of social justice and protection of low socioeconomic groups. ${ }^{39}$ Finally, legal assessments indicate that advance notice of planned policies is recommended. ${ }^{39}$

\section{Implementation process and policy impact}

The eight existing studies related to smoke-free building policy adoption and policy impact suggest that it is a sustained process.
One study reported on efforts related to a 6-year campaign, initiated in 2004, to move MUH providers in Oregon towards the adoption of smoke-free policies. ${ }^{28}$ Several studies emphasise the importance of working closely with public and privatesector stakeholders, ${ }^{28}{ }^{41-43}$ and two studies reported better progress with MUH operators when the business case, and not the public health case, was emphasised for implementing smoke-free

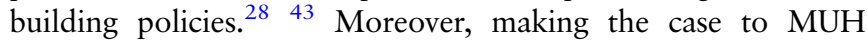
operators does not necessarily have to be resource-intensive. For example, one study found that mailing information about smoke-free MUH to MUH operators reduced concerns about adopting smoke-free building policies. ${ }^{26}$ Another study suggested that having a fellow operator's perspective was more convincing than fact sheets or information from health department staff. ${ }^{43}$ Additionally, other studies have suggested that local data collection helps improve understanding of MUH resident preferences, ${ }^{28}{ }^{41}$ existing access to and preferences for cessation support among smokers, ${ }^{18}$ and the perspectives of MUH operators and how to develop educational messages to inform change. ${ }^{28}{ }^{41}$ Finally, in addition to top-down approaches involving policymakers and MUH operators, the importance of media strategies to educate residents about smoke-free building policies has been highlighted. ${ }^{42} 43$

Only one resident survey included postimplementation data. In Portland, Oregon, subsidised housing residents were surveyed after the implementation of a smoke-free building policy that included smoke-free zones within 25 feet of buildings. ${ }^{12} 22$ In a survey administered approximately 4 months after policy implementation, ${ }^{12} 74 \%$ of residents reported being either 'very' or 'somewhat' happy with the policy; there were significant differences by smoking status, with policy satisfaction reported by $92 \%$ of never-smokers, $85 \%$ of former smokers and $30 \%$ of current smokers. ${ }^{12}$ The study also reported findings from focus groups with residents $(n=23)$, including current smokers $(n=5)$, former smokers $(n=10)$ and never-smokers $(n=8)$. Non-smokers were pleased about the policy's potential effects for promoting health, fire safety and building cleanliness. Although some smokers recognised positive aspects of the policy, ${ }^{12}$ many felt that the policy was unfair.

In a second study, ${ }^{22}$ more detailed findings from the aforementioned study were reported, as well as findings from a second survey conducted among a subsample $(n=440)$ of the same residents approximately 16 months after policy implementation. Only $17 \%$ of residents reported frequent exposure to SHS after policy implementation, compared with $41 \%$ before the policy. Additionally, self-reported quit rates dramatically increased (annualised rate postpolicy: 14.7\%; average annual rate for 5 years prepolicy announcement: $2.6 \%$ ), and reported cigarette consumption declined. Many of these current or former smokers reported that the building policy was part of the reason for their behaviour change $(68 \%$ for those who quit; $58 \%$ for those who reduced consumption). ${ }^{22}$ Additionally, knowledge of the policy's application to indoor units and selfreported compliance were high; 59\% of smokers smoked in their units before the policy compared with $17 \%$ after policy implementation. $^{22}$ As noted in the MUH Operators Studies section, managers reported few complaints from smoking or non-smoking tenants and only 11 evictions over an 18-month period. Ten of 11 managers found policy enforcement difficult, especially if smoking took place in tenant units. ${ }^{22}$

\section{DISCUSSION}

The findings from this review underscore the critical importance of implementing smoke-free building policies to reduce SHS 
exposure in MUH. The existing peer-reviewed literature suggests that smoke-free MUH policies are supported by most MUH residents, ${ }^{11} 1315172021$ are likely to yield considerable cost savings for individual MUH operators and society, ${ }^{36} 37$ and may improve cessation outcomes among current smokers. ${ }^{22}$ However, policy prevalence remains low. ${ }^{15} 212^{23-27}$ Many MUH owners and managers have misconceptions about barriers to implementing such policies, including the legality of such policies, concerns over increased vacancy and tenant turnover, and compliance and enforcement complications. ${ }^{15} 24-27$ These findings underscore the importance of public health efforts to educate MUH operators about the health and economic benefits of prohibiting smoking on their properties, including efforts to disseminate information on the experiences of their peers who have already implemented such policies. Support and guidance for MUH operators is of particular importance for those working with vulnerable populations.

\section{Summary of the existing scientific literature}

Studies of MUH residents suggest that most already have smokefree home rules, ${ }^{10} 17$ including a large proportion of smokers. ${ }^{11}$ However, a considerable proportion of $\mathrm{MUH}$ residents are exposed to SHS incursions in their home, ${ }^{10} \quad 11 \quad 13 \quad 15 \quad 20-22$ making them vulnerable to a variety of health consequences associated with this preventable health hazard. ${ }^{2}$ The available evidence also indicates that a majority of $\mathrm{MUH}$ residents support smoke-free building policies, ${ }^{10} \begin{array}{lllll}11 & 13 & 15 & 17 & \text { including }\end{array}$ many smokers. ${ }^{11} 1720$ Studies of residents following implementation of such policies suggest relatively high compliance and a beneficial impact, including enhanced cessation behaviours among smokers and reduced SHS exposure among non-smokers. $^{22}$

Studies of MUH operators suggest that these individuals often do not recognise SHS transfer in MUH as an issue. ${ }^{15} 25$ Additionally, many have incomplete information about the legal and economic ramifications of implementing smoke-free building policies, ${ }^{15}{ }^{24-27}$ as well as misperceptions about resident preferences towards such policies. Given more complete information, operators tend to be supportive of, and interested in, implementing smoke-free policies in their buildings. Issues related to smoke-free MUH policy compliance and enforcement have not been fully explored. However, the available evidence suggests that most MUH operators who have implemented smoke-free building policies report having no difficulty with policy enforcement, ${ }^{15}$ with most employing methods that require little investment of money or staff time, such as sending written warning letters. 2225

Air monitoring studies make a clear case that SHS exposure in MUH is high and more prominent among residents living in low-income housing. Children living in MUH with smoke-free home rules still showed evidence of tobacco smoke exposure, indicating objective evidence of SHS incursions. ${ }^{33}$ Additionally, buildings with elderly, disabled smokers had higher levels of exposure. ${ }^{34}$ Studies documenting SHS transfer and highlighting the many factors that impact SHS transfer also confirm that smoke-free building policies are the most effective method to fully reduce SHS exposure in MUH. ${ }^{19} 29$

Cost analyses, though limited in number, suggest that the considerable economic benefits of smoke-free building policies outweigh any implementation costs. ${ }^{36} 37$ Legal analyses, though also limited, have made it clear that there are no legal issues preventing the implementation of smoke-free building policies; in fact, such policies likely will protect owners and operators from liability related to SHS exposure. ${ }^{40}$ Finally, data on smoke-free policy implementation are limited; however, the single study that has been conducted suggests successes in enforcement and compliance, as well as higher quit rates, reduced consumption and reduced SHS exposure among residents following policy implementation. $^{22}$

\section{Gaps in the existing scientific literature}

This review also identified some gaps in the existing literature. For example, most existing studies utilised self-reported data from residents or operators, have relied on relatively small sample sizes and have generally not used validated survey instruments. As a result, measurement approaches are inconsistent across studies; common measurement approaches would facilitate comparisons across studies, including for comparisons of reported SHS exposure, types of building policies and prevalence of smoke-free policies. Additionally, inconsistencies in assessed demographics may complicate interpretation and comparability. Larger sample sizes and nationally representative data could ultimately improve understanding of demographic variation in resident experiences, preferences and related behaviours. Additionally, state and local level data are important for informing localised efforts to implement smoke-free policies.

Existing gaps are also apparent by geography. In particular, few studies have been conducted in the southern USA, with most studies being conducted in states with historically progressive tobacco control efforts, including California, Oregon, New York and Minnesota. Additionally, few nationally representative studies exist that account for variations in MUH residency characteristics across regions. Data related to the impact of smoke-free MUH policies on resident displacement, particularly in the context of disparities, as well as the impact of smoke-free building policies on health outcomes, are also limited. Finally, there is limited literature on the return on investment that smoke-free policies could provide for MUH operators. While research has established that smoke-free buildings decrease renovation and smoking-attributable fire costs, actual savings have not been quantified.

Despite these existing gaps, the current literature provides sufficient evidence for current and future actions to eliminate SHS exposure in MUH.

\section{Opportunities for future research to inform policy and practice}

As smoke-free MUH policies continue to be implemented across the USA, evaluation is essential to understand the impact of policies. Similar to the manner in which findings from early evaluations of smoke-free workplaces, restaurants and bars helped to inform policy development, implementation and enforcement, findings from evaluations of smoke-free MUH have the potential to inform public health policy, planning and practice. For example, studies documenting declines in SHS exposure, ${ }^{35}$ improvements in health outcomes, ${ }^{44} 45$ high rates of compliance $^{46}$ and lack of adverse economic impacts ${ }^{47}$ provided a critical evidence base for the adoption and sustainment of smoke-free workplace, restaurant and bar policies at the local, state, national and international levels. In the context of smokefree MUH, process evaluations will inform procedures such as MUH operator education, resident notices, cessation support and enforcement outcomes. Further defining the economic benefits of these policies, such as estimated savings from insurance companies due to decreased fire risk, could be informative for MUH operators considering implementing smoke-free MUH policies. Legal studies, including those initiated by non-smokers involuntarily exposed to SHS in MUH, as well as smokers who 
have challenged the implementation of such policies, would also be beneficial. Outcome evaluations, including longitudinal studies, are also critical to enhance understanding impact, and could include evaluations of resident SHS exposure, resident smoking behaviour and policy compliance, costs to operators, and short-term and long-term health indicators. The most informative outcome evaluations will include preimplementation and postimplementation data with more than one postimplementation time point and appropriate controls for comparison. While longitudinal studies may be most informative, the transient nature of the study population may result in these studies being difficult and costly to complete. Sampling of MUH residents could be improved to include randomised sampling approaches to identify respondents. One option for developing a random sample of MUH residents would be to identify or develop a list of MUH in the study area and use address-based sampling to identify residents.

SHS exposure has been evaluated via resident self-report, but it is important for evaluations to include more objective measures of SHS exposure, such as $\mathrm{PM}_{2.5}$, nicotine or cotinine. Assessments using these types of objective measures have provided a useful evidence base for informing the adoption and retention of smoke-free policies in public areas, such as restaurants and bars. ${ }^{48}$ It may also be useful to estimate the amount of excess risk of SHS exposure for those who live in MUH compared with private housing. Assessments of smoking behaviour should include reports of smoking frequency and quitting behaviour. Outcome evaluations are also warranted to examine potential consequences for owners/operators, including vacancy and turnover. Particular attention should be paid to how compliance and enforcement related to smoke-free policies affects lower income MUH residents. Understanding resident perspectives may be especially important for implementation of policies in public and subsidised housing. One group working with public housing residents in the District of Columbia to improve a variety of health services noted the importance of a community-based participatory approach, empowering residents to take charge of planning and advocacy efforts designed to address their health needs. ${ }^{49}$ Without such an inclusive approach, residents feel that they have no voice, ${ }^{49}$ making them less likely to participate in policy implementation and evaluation efforts.

\section{Limitations}

This is the first comprehensive review of research and evaluation related to smoke-free MUH. However, some limitations of this study exist. First, the generalisability of the findings may not extend beyond the USA. Second, the conclusions about subpopulations are limited due to limited sample sizes and inconsistencies between studies. Third, many of the studies utilised convenience samples, and thus, external validity may be limited. Fourth, prevalence estimates for MUH operator studies may not be comparable between populations due to self-selection into studies and small sample sizes. Finally, the review focused on peer-reviewed literature and does not include evidence from grey literature such as legal documents or unpublished reports.

\section{CONCLUSION}

These findings underscore the importance of smoke-free building policies for protecting MUH residents, visitors and employees from a deadly and preventable health hazard. To date, existing literature has primarily focused on self-reported, crosssectional studies of MUH residents and operators; some studies of environmental markers, biomarkers and economic indicators have also been conducted. Although existing research and experience provides ample justification for action, future research can address knowledge gaps in the impact of smokefree MUH building policies on smoking behaviours and health outcomes, as well as factors associated with policy compliance and enforcement to further inform public health policy, planning and practice.

\section{What this paper adds}

- This is the first study to identify, review and synthesise the existing peer-reviewed literature on smoke-free multiunit housing (MUH) in the USA.

- The findings reveal that existing literature has focused on self-reported, cross-sectional studies of MUH residents and operators; some studies of environmental markers, biomarkers and economic indicators have also been conducted.

- Although existing research and experience provides ample justification for smoke-free MUH policies, future research can address knowledge gaps in the impact of smoke-free MUH building policies on smoking behaviours and health outcomes, as well as factors associated with policy compliance and enforcement to further inform public health policy, planning and practice.

Acknowledgements The development of this paper was supported in part through monitoring and evaluation contracts to ICF International (Contract \#s: 200-2007-22643-0003 and 200-2011-F-42029) for work on the Communities Putting Prevention to Work and Community Transformation Grants.

Contributors All coauthors have made substantial contributions to the creation of the manuscript and take full responsibility for its contents. BAK was involved in methodology and writing. JHV was involved in methodology, literature review and writing. KS was involved in methodology, literature review and writing.

Funding U.S. Department of Health and Human Services-Centers for Disease Control and Prevention, 200-2007-22643-0003, 200-2011-F-42029.

Competing interests None.

Provenance and peer review Not commissioned; externally peer reviewed.

\section{REFERENCES}

1 United States Department of Health and Human Services. The health consequences of smoking - 50 years of progress: a report of the surgeon general. Rockville, MD: U.S. Department of Health and Human Services, Public Health Service, Office of the Surgeon General, 2014.

2 United States Department of Health and Human Services. The health consequences of involuntary exposure to tobacco smoke: a report of the surgeon general. Atlanta, Georgia: U.S. Department of Health and Human Services, Centers for Disease Control and Prevention, Coordinating Center for Health Promotion, National Center for Chronic Disease Prevention and Health Promotion, Office on Smoking and Health, 2006.

3 Centers for Disease Control and Prevention. State Tobacco Activities Tracking and Evaluation (STATE) System: Smokefree Indoor Air Fact Sheet. Department of Health and Human Services, Centers for Disease Control and Prevention, National Center for Chronic Disease Prevention and Health Promotion, Office on Smoking and Health, 2014.

4 Klepeis NE, Nelson WC, Ott WR, et al. The national human activity pattern survey (NHAPS): a resource for assessing exposure to environmental pollutants. J Expo Anal Environ Epidemiol 2001;11:231-52.

5 King BA, Travers MJ, Cummings KM, et al. Secondhand smoke transfer in multiunit housing. Nicotine Tob Res 2010;12:1133-41.

6 King BA, Babb SD, Tynan MA, et al. National and state estimates of secondhand smoke infiltration among U.S. multiunit housing residents. Nicotine Tob Res 2013;15:1316-21.

7 United States Department of Housing and Urban Development. Resident Characteristics Report. 2014. http://portal.hud.gov/hudportal/HUD?src=/program_ offices/public_indian_housing/systems/pic/50058/rcr (accessed 1 Apr 2014). 
8 United States Department of Housing and Urban Development. Memo to regional directors; state and area coordinators; public housing hub directors; program center coordinators; troubled agency recovery center directors; special applications center director; public housing agencies; resident management corporations; healthy homes representatives, 17 July 2009. Notice: PIH-2009-21 (HA). http://www.hud. gov/offices/pih/publications/notices/09/pih2009-21.pdf (accessed 15 Feb 2014).

9 American Nonsmokers' Rights Foundation. U.S. Local Laws and Policies Restricting or Prohibiting Smoking in Private Units of Multi-Unit Housing, 3 July 2014. 2014. http://www.no-smoke.org/pdf/smokefreemuh.pdf (accessed 21 Sep 2014).

10 Baezconde-Garbanati LA, Weich-Reushe K, Espinoza L, et al. Secondhand smoke exposure among Hispanics/Latinos living in multiunit housing: exploring barriers to new policies. Am J Health Promot 2011;25:S82-90.

11 Ballor DL, Henson H, Macguire K. Support for no-smoking policies among residents of public multiunit housing differs by smoking status. J Community Health 2013;38:1074-80.

12 Drach LL, Pizacani BA, Rohde $K \mathrm{~L}$, et al. The acceptability of comprehensive smoke-free policies to low-income tenants in subsidized housing. Prev Chronic Dis 2010;7:A66.

13 Hennrikus D, Pentel PR, Sandell SD. Preferences and practices among renters regarding smoking restrictions in apartment buildings. Tob Control 2003;12:189-94

14 Hewett MJ, Ortland WH, Brock BE, et al. Secondhand smoke and smokefree policies in owner-occupied multi-unit housing. Am J Prev Med 2012;43:S187-96.

15 Hewett MJ, Sandell SD, Anderson J, et al. Secondhand smoke in apartment buildings: renter and owner or manager perspectives. Nicotine Tob Res 2007;9: S39-47.

16 Hood NE, Ferketich AK, Klein EG, et al. Associations between self-reported in-home smoking behaviours and surface nicotine concentrations in multiunit subsidised housing. Tob Control 2014;23:27-32.

17 Hood NE, Ferketich AK, Klein EG, et al. Individual, social, and environmental factors associated with support for smoke-free housing policies among subsidized multiunit housing tenants. Nicotine Tob Res 2013;15:1075-83.

18 Hood NE, Ferketich AK, Klein EG, et al. Smoking behaviors and cessation interests among multiunit subsidized housing tenants, Columbus, Ohio, 2011. Prev Chronic Dis 2013;10:E108; quiz E108.

19 Hood NE, Wewers ME, Ferketich AK, et al. Predictors of voluntary home-smoking restrictions and associations with an objective measure of in-home smoking among subsidized housing tenants. Am J Health Promot 2013;28:97-104.

20 King BA, Cummings KM, Mahoney MC, et al. Multiunit housing residents' experiences and attitudes toward smoke-free policies. Nicotine Tob Res 2010;12:598-605.

21 Licht AS, King BA, Travers MJ, et al. Attitudes, experiences, and acceptance of smoke-free policies among US multiunit housing residents. Am J Public Health 2012;102:1868-71.

22 Pizacani BA, Maher JE, Rohde $\mathrm{K}$, et al. Implementation of a smoke-free policy in subsidized multiunit housing: effects on smoking cessation and secondhand smoke exposure. Nicotine Tob Res 2012;14:1027-34.

23 Wilson KM, Torok M, McMillen $\mathrm{R}$, et al. Tobacco smoke incursions in multi-unit housing. Am J Public Health 2014;104:1445-53.

24 Cramer ME, Roberts S, Stevens E. Landlord attitudes and behaviors regarding smoke-free policies: implications for voluntary policy change. Public Health Nurs 2011:28:3-12.

25 Jackson SL, Bonnie RJ. A systematic examination of smoke-free policies in multiunit dwellings in Virginia as reported by property managers: implications for prevention. Am J Health Promot 2011;26:37-44.

26 King BA, Mahoney MC, Cummings KM, et al. Intervention to promote smoke-free policies among multiunit housing operators. J Public Health Manag Pract 2011;17: E1-8.
27 King BA, Travers MJ, Cummings KM, et al. Prevalence and predictors of smoke-free policy implementation and support among owners and managers of multiunit housing. Nicotine Tob Res 2010;12:159-63.

28 Pizacani B, Laughter D, Menagh $\mathrm{K}$, et al. Moving multiunit housing providers toward adoption of smoke-free policies. Prev Chronic Dis 2011;8:A21.

29 Bohac DL, Hewett MJ, Hammond SK, et al. Secondhand smoke transfer and reductions by air sealing and ventilation in multiunit buildings: PFT and nicotine verification. Indoor Air 2011;21:36-44.

30 Dacunto PJ, Cheng KC, Acevedo-Bolton V, et al. Identifying and quantifying secondhand smoke in multiunit homes with tobacco smoke odor complaints. Atmospheric Environ 2013;71:399-407.

31 Kraev TA, Adamkiewicz G, Hammond SK, et al. Indoor concentrations of nicotine in low-income, multi-unit housing: associations with smoking behaviours and housing characteristics. Tob Control 2009;18:438-44.

32 Levy DE, Rigotti NA, Winickoff JP. Tobacco smoke exposure in a sample of Boston public housing residents. Am J Prev Med 2013;44:63-6.

33 Wilson KM, Klein JD, Blumkin AK, et al. Tobacco smoke exposure in children who live in multiunit housing. Pediatrics 2011;127:85-92.

34 Arku RE, Adamkiewicz G, Vallarino J, et al. Seasonal variability in environmental tobacco smoke exposure in public housing developments. Indoor Air Published Online First: 14 May 2014. doi:10.1111/ina.12121.

35 Centers for Disease Control and Prevention. Indoor air quality in hospitality venues before and after implementation of a clean indoor air law-Western New York, 2003. MMWR Morb Mortal Wkly Rep 2004;53:1038-41.

36 King BA, Peck RM, Babb SD. Cost savings associated with prohibiting smoking in U.S. Subsidized housing. Am J Prev Med 2013;44:631-4.

37 Ong MK, Diamant AL, Zhou Q, et al. Estimates of smoking-related property costs in California multiunit housing. Am J Public Health 2012;102:490-3.

38 Kline RL. Smoke knows no boundaries: legal strategies for environmental tobacco smoke incursions into the home within multi-unit residential dwellings. Tob Control 2000;9:201-5.

39 Winickoff JP, Gottlieb M, Mello MM. Regulation of smoking in public housing. N Engl J Med 2010;362:2319-25.

40 Ezra DB. "Get your ashes out of my living room!": controlling tobacco smoke in multi-unit residential housing. Rutgers Law Rev 2001;54:135-89.

41 Satterlund TD, Treiber J, Kipke R, et al. A qualitative evaluation of 40 voluntary, smoke-free, multiunit, housing policy campaigns in California. Tob Control 2014;23:491-5

42 Modayil MV, Consolacion TB, Isler J, et al. Cost-effective smoke-free multiunit housing media campaigns: connecting with local communities. Health Promot Pract 2011;12(6 Suppl 2):173S-85S

43 Satterlund TD, Treiber J, Cassady D. Navigating local smoke-free multi-unit housing policy adoption. J Drug Educ 2013;43:33-47.

44 Goodman P, Agnew M, McCaffrey M, et al. Effects of the Irish smoking ban on respiratory health of bar workers and air quality in Dublin pubs. Am J Respir Crit Care Med 2007;175:840-5.

45 Menzies D, Nair A, Williamson PA, et al. Respiratory symptoms, pulmonary function, and markers of inflammation among bar workers before and after a legislative ban on smoking in public places. JAMA 2006;296:1742-8.

46 Hyland A, Cummings KM, Wilson MP. Compliance with the New York City Smoke-Free Air Act. J Public Health Manag Pract 1999;5:43-52.

47 Cowling DW, Bond P. Smoke-free laws and bar revenues in California: the last call. Health Econ 2005; 14:1273-81.

48 Connolly GN, Carpenter CM, Travers MJ, et al. How smoke-free laws improve air quality: a global study of Irish pubs. Nicotine Tob Res 2009;11:600-5.

49 Council KD, Wilson JC, Harris BM, et al. Improving health services for residents through community-based participatory research: a public housing leadership perspective. Prog Community Health Partnersh 2013;7:89-93. 